\title{
Review
}

Michele Mussap* and Vassilios Fanos

\section{Could metabolomics drive the fate of COVID-19 pandemic? A narrative review on lights and shadows}

https://doi.org/10.1515/cclm-2021-0414

Received April 6, 2021; accepted July 19, 2021;

published online July 30, 2021

\begin{abstract}
Human Severe Acute Respiratory Syndrome CoronaVirus 2 (SARS-CoV-2) infection activates a complex interaction host/virus, leading to the reprogramming of the host metabolism aimed at the energy supply for viral replication. Alterations of the host metabolic homeostasis strongly influence the immune response to SARS-CoV-2, forming the basis of a wide range of outcomes, from the asymptomatic infection to the onset of COVID-19 and up to life-threatening acute respiratory distress syndrome, vascular dysfunction, multiple organ failure, and death. Deciphering the molecular mechanisms associated with the individual susceptibility to SARS-CoV-2 infection calls for a system biology approach; this strategy can address multiple goals, including which patients will respond effectively to the therapeutic treatment. The power of metabolomics lies in the ability to recognize endogenous and exogenous metabolites within a biological sample, measuring their concentration, and identifying perturbations of biochemical pathways associated with qualitative and quantitative metabolic changes. Over the last year, a limited number of metabolomics- and lipidomics-based clinical studies in COVID-19 patients have been published and are discussed in this review. Remarkable alterations in the lipid and amino acid metabolism depict the molecular phenotype of subjects infected by SARS-CoV-2; notably, structural and functional data on the lipids-virus interaction may open new perspectives on targeted therapeutic interventions. Several
\end{abstract}

*Corresponding author: Michele Mussap, MD, Laboratory Medicine, Department of Surgical Sciences, School of Medicine, University of Cagliari, Cittadella Universitaria S.S. 554, 09042 Monserrato, Italy, Phone: +39705103403, Mobile: +393389352966 ,

E-mail: mumike153@gmail.com. https://orcid.org/0000-0002-34171284

Vassilios Fanos, Neonatal Intensive Care Unit, Department of Surgical Sciences, School of Medicine, University of Cagliari, Monserrato, Italy limitations affect most metabolomics-based studies, slowing the routine application of metabolomics. However, moving metabolomics from bench to bedside cannot imply the mere determination of a given metabolite panel; rather, slotting metabolomics into clinical practice requires the conversion of metabolic patient-specific data into actionable clinical applications.

Keywords: amino acids; COVID-19; lipidomics; metabolomics; system biology.

\section{Introduction}

When the human body is infected with a virus, including the Severe Acute Respiratory Syndrome CoronaVirus 2 (SARS-CoV-2), both host and virus impact each other's metabolism. Indeed, host cells serve viral replication and survival with the consequent virus-induced host metabolic reprogramming [1]. The immune response to SARS-CoV-2 and other viruses strictly depends on the metabolic homeostasis; for example, cytokine maturation and T-cell proliferation are promoted by byproducts of glycolysis [2],

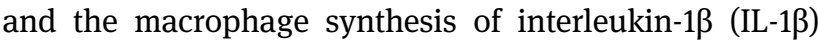
requires the availability of 3-phosphoglyceric acid, a precursor of the de novo serine synthesis [3]. In Coronavirus Disease 2019 (COVID-19) patients with type-2 diabetes mellitus or metabolic syndrome, hyperglycemia hampers the regular production of type-1 interferons (IFNs-1), a family of cytokines encompassing 13 IFN- $\alpha$ subtypes, IFN- $\beta$, IFN$\omega$, IFN- $\kappa$, and IFN- $\varepsilon$ [4]. IFNs-1 are potent antiviral cytokines produced by innate immune cells and play a key role in protecting against the systemic spread of viruses [5]; it is not surprising that low levels of IFNs-1 strongly correlated with COVID-19 severity [6]. The impaired synthesis of IFNs-1 alters the urea cycle, and reduces the ornithine and arginine availability necessary to regulate the adaptive immunity and limit tissue damage. Additional examples of the relationship between metabolism and the immune response are: (a) the activation of the mammalian target of rapamycin complex 1 (mTORC1) by branched-chain amino acids 
(BCAA) and other essential amino acids; (b) the role of glutamine for mTORC1 function; (c) the tryptophan degradation induced by interleukin-6 (IL-6). Lipids are considerably involved in the immune response's modulation, playing a key role in the inflammatory signaling pathways.

\section{The role of metabolomics in the context of COVID-19 pandemic}

Over the past years, metabolomics has moved far beyond the stage of being an emerging field within the "omics" sciences; notions, such as the "molecular phenotype" of a given biofluid or tissue, and the individual "metabotype" have now become well known within the scientific community. The power of metabolomics consists of the ability to recognizing endogenous and exogenous metabolites within a biological sample, measuring their concentration, and identifying perturbations of biochemical pathways associated with qualitative and quantitative metabolic changes. As very recently stated, metabolomics can be considered the stethoscope of the 21st century [7]. A challenging opportunity for metabolomics may be the evaluation of the saliva metabolome and its changes associated with the course and the severity of COVID-19. In particular, salivary metabolomics can reflect the exact mechanisms underlying the temporary loss of taste (ageusia) and smell (anosmia) that affect patients with COVID-19 [8]. SARS-CoV-2 targets non-neuronal cells in the olfactory epithelium and olfactory bulb expressing SARS-CoV-2 entry-associated transcripts and their associated proteins (ACE2 receptor and Transmembrane Serine Protease 2-TMPRSS2), inducing anosmia [9]. Metabolomic studies unveiled that subjects who are insensitive to the perception of oleic acid exhibited higher levels of acetate and butyrate in saliva, along with a reduced concentration of lysine and fatty acids [10]. In particular, significant metabolic differences were found between sensitive and insensitive oleic acid perceivers; the former exhibit increased salivary levels of acetate, propionate, formate, lysine, valine, and GABA, while the latter higher concentrations of galactose, glucose, lactate, threonine, phosphocholine, and ethanolamine [11]. Additionally, it was postulated that L-Arginine could modulate bitter taste function and suppress the quinine's bitterness by blocking the T2R4 receptor [12]. Disadvantages related with metabolomics in saliva samples consist of: (a) the low concentration of metabolites, compared with that in other biological fluids (serum, plasma, urine); (b) the high biological variability due to large diurnal fluctuations in metabolites concentration; and (c) the presence of oral injuries with potential blood contamination [13]. However, the study of the salivary metabolome is a unique source of metabolic information on the nasopharyngeal and body's response to the viral infection; thus, efforts to improve the current performances are required. First, there is the need to standardize the collection of saliva samples by using specific commercially available devices containing absorbing materials (e.g., inert polymers) or specific swabs capturing cells and saliva in the mouth [14]. In addition, standardization of transport and storage is crucial to prevent conformational changes of metabolites and polypeptides. It has been suggested that saliva samples stabilization during transport and storage can be obtained by drying samples in presence on non-reducing sugars [15]. Emerging technologies, such as pulsed and magnetic field gradients (programmed set of changing magnetic gradients) in nuclear magnetic resonance (NMR) spectroscopy-based metabolomic studies, may ameliorate the sensitivity, facilitating the utilization of saliva in metabolomic studies [16]. Finally, rigorous recommendations on a diet and fasting time standardization before sample collection may contribute to overcoming current pitfalls [17]. Compared to the impressive number of clinical studies in patients with COVID-19, targeted or untargeted metabolomic studies profiling COVID-19 patients represent a small portion. Table 1 illustrates the main characteristics of the studies included in this review.

\section{Lipids and lipidomic studies in SARS-CoV-2 infection}

\section{The link between lipids, viral infection, and the host immunological response}

Lipid metabolism is a galaxy consisting of myriad of metabolites, closely interconnected each other, and hundreds of specific pathways supporting the life-cycle of cells, tissues, and organs. Beyond the well-known function of lipids as structural components of biological membranes and source of energy, they may act directly as bioactive signaling molecules, named lipid mediators [18]; early, bioactive lipids were considered as antiviral drugs [19]. Thus, it is not surprising that lipids are strongly involved in the interplay between SARS-CoV-2 cellular infection and the host metabolic and immunological response [20]. Lipid mediators can be classified into three categories (Table 2); their half-life is relatively short, ranging from seconds to very few minutes [21]. The driver promoting the synthesis of lipid mediators is the inflammation arising from acute or chronic organ/tissue injuries or infections; as a result, lipid 
Table 1: Characteristics of the main metabolomics-based studies in COVID-19.

\begin{tabular}{|c|c|c|c|c|}
\hline Author [ref.] & Patient cohort & $\begin{array}{l}\text { Biological } \\
\text { matrix }\end{array}$ & Time of sample collection & Method \\
\hline Mounayar [10] & $\begin{array}{l}11 \text { subjects who could perceive taste } \\
\text { sensitivity to } \mathrm{C} 18: 1 \text { at low concentration; } \\
11 \text { subjects who could not perceive taste } \\
\text { sensitivity to } \mathrm{C} 18: 1 \text { at high concentration }\end{array}$ & Saliva & $\begin{array}{l}\text { Resting saliva was collected } \\
\text { between } 6 \text { and } 7 \text { p.m. on three } \\
\text { consecutive days }\end{array}$ & $\begin{array}{l}\text { Untargeted }{ }^{1} \mathrm{H} \text { NMR } \\
\text { spectroscopy }\end{array}$ \\
\hline Mounayar [11] & $\begin{array}{l}22 \text { subjects retrospectively classified as } \\
\text { sensitive or insensitive to C18:1 by a } \\
\text { stimulation with } 2 \text { emulsions, the first one } \\
\text { with C18:1 and the second one without } \\
\text { C18:1 }\end{array}$ & Saliva & $\begin{array}{l}\text { All the sessions took place in the } \\
\text { evening }\end{array}$ & $\begin{array}{l}\text { Untargeted }{ }^{1} \mathrm{H} \text { NMR } \\
\text { spectroscopy }\end{array}$ \\
\hline Schwarz [54] & $\begin{array}{l}20 \text { severe COVID requiring ICU admission; } \\
18 \text { moderate COVID; } 19 \text { healthy subjects }\end{array}$ & Serum & $\begin{array}{l}3 \pm 1 \text { and } 4 \pm 2 \text { days post- } \\
\text { admission for moderate and se- } \\
\text { vere COVID, respectively }\end{array}$ & Targeted LC-MS/MS \\
\hline Barberis [55] & $\begin{array}{l}19 \text { critical COVID; } 84 \text { non-critical COVID; } 20 \\
\text { non-critical non-COVID pneumonia; } 12 \\
\text { critical non-COVID pneumonia; } 26 \text { healthy } \\
\text { subjects }\end{array}$ & Plasma & Not specified & $\begin{array}{l}\text { Untargeted UPLC-MS/MS and } \\
\text { GC-TOF-MS }\end{array}$ \\
\hline $\mathrm{Wu}[56]$ & $\begin{array}{l}9 \text { COVID with fatal outcome; } 11 \text { severe } \\
\text { COVID; } 14 \text { mild COVID; } 10 \text { healthy subjects }\end{array}$ & $\begin{array}{l}\text { EDTA } \\
\text { plasma }\end{array}$ & $\begin{array}{l}\text { Serial samples collected over } \\
\text { the course of the disease every } \\
3-5 \text { days }\end{array}$ & Targeted LC-ESI-MS/MS \\
\hline Overmyer [57] & $\begin{array}{l}51 \text { critical COVID (ICU); } 51 \text { non-critical } \\
\text { COVID; } 16 \text { critical non-COVID (ICU); } 10 \text { non- } \\
\text { critical non-COVID }\end{array}$ & Plasma & $\begin{array}{l}\text { Time of patient's enrollment; } \\
\text { single timepoint collection }\end{array}$ & $\begin{array}{l}\text { Targeted metabolomics GC-MS; } \\
\text { lipidomics LC-MS/MS }\end{array}$ \\
\hline Bruzzone [58] & $\begin{array}{l}263 \text { COVID training cohort; } 135 \text { COVID } \\
\text { validation cohort; } 280 \text { healthy subjects } \\
\text { (samples collected in pre-COVID times) }\end{array}$ & Serum & $\begin{array}{l}\text { Admission time to hospital; sin- } \\
\text { gle timepoint collection }\end{array}$ & ${ }^{1}$ H NMR spectroscopy \\
\hline Thomas [60] & $\begin{array}{l}33 \text { COVID; } 16 \text { SARS-CoV-2 negative, } \\
\text { including those never positive and conva- } \\
\text { lescent plasma donors }\end{array}$ & Serum & Not specified & $\begin{array}{l}\text { Targeted and untargeted } \\
\text { UPLC-MS }\end{array}$ \\
\hline Shen [61] & $\begin{array}{l}28 \text { severe COVID; } 37 \text { non-severe COVID; } 25 \\
\text { non-COVID; } 28 \text { healthy subjects }\end{array}$ & Serum & $\begin{array}{l}\text { Few days after hospital admis- } \\
\text { sion; single timepoint collection }\end{array}$ & $\begin{array}{l}\text { Targeted and untargeted RP } \\
\text { UPLC-MS/MS and HILIC } \\
\text { UPLC-MS/MS }\end{array}$ \\
\hline Roberts [62] & $\begin{array}{l}71 \text { mild COVID; } 49 \text { severe COVID (31 with } \\
\text { fatal outcome) }\end{array}$ & Serum & At admission and diagnosis & Untargeted LC-MS/MS \\
\hline Song [64] & $\begin{array}{l}13 \text { severe COVID; } 19 \text { moderate COVID; } 18 \\
\text { mild COVID; } 26 \text { healthy subjects }\end{array}$ & $\begin{array}{l}\text { EDTA } \\
\text { plasma }\end{array}$ & $\begin{array}{l}\text { Within } 24 \mathrm{~h} \text { upon hospital } \\
\text { admission }\end{array}$ & $\begin{array}{l}\text { Targeted lipidomics by RP } \\
\text { LC-MRM-MS; untargeted } \\
\text { metabolomics by RP UPLC-TOF- } \\
\text { MS/MS }\end{array}$ \\
\hline $\mathrm{Xu}[65]$ & $\begin{array}{l}69 \text { severe and } 34 \text { mild-to-moderate COVID } \\
\text { (enrolled } 3 \text { months after hospital } \\
\text { discharge); } 27 \text { healthy donors }\end{array}$ & Plasma & $\begin{array}{l}\text { Single timepoint collections af- } \\
\text { ter } 3 \text { months from hospital } \\
\text { discharge }\end{array}$ & Untargeted LC-ESI-MS/MS \\
\hline Caterino [68] & $\begin{array}{l}17 \text { severe COVID; } 16 \text { moderate COVID; } 20 \\
\text { mild COVID }\end{array}$ & Serum & $\begin{array}{l}\text { Multicentre single timepoint } \\
\text { collection }\end{array}$ & Targeted LC-MS \\
\hline Delafiori [69] & $\begin{array}{l}442 \text { COVID; } 23 \text { suspicious COVID; } 37 \\
\text { symptomatic but RT PCR, clinical and } \\
\text { imaging negative; } 313 \text { asymptomatic } \\
\text { controls }\end{array}$ & Plasma & $\begin{array}{l}\text { Multicentre multiple sample } \\
\text { collection; time of hospital } \\
\text { admission and during } \\
\text { hospitalization }\end{array}$ & $\begin{array}{l}\text { Untargeted direct Infusion- } \\
\text { Mass spectrometry (DI-MS) }\end{array}$ \\
\hline Snider [71] & $\begin{array}{l}30 \text { mild COVID; } 30 \text { severe COVID; } 30 \text { COVID } \\
\text { with fatal outcome }\end{array}$ & Plasma & $\begin{array}{l}\text { Not specified; single timepoint } \\
\text { collection }\end{array}$ & Untargeted UPLC-ESI-MS/MS \\
\hline Blasco [74] & 55 COVID positive; 45 non-COVID & Plasma & $\begin{array}{l}\text { After SARS-CoV-2 RT PCR: } \\
3.6 \pm 2.6 \text { days in COVID positive; } \\
2.6 \pm 1.8 \text { days in COVID negative }\end{array}$ & Targeted LC-HR-MS \\
\hline Kimhofer [75] & 17 COVID positive; 25 healthy subjects & Plasma & $\begin{array}{l}\text { Not specified; single timepoint } \\
\text { collection }\end{array}$ & $\begin{array}{l}{ }^{1} \text { H NMR spectroscopy; } \\
\text { UPLC-MS for amino acids }\end{array}$ \\
\hline Sindelar [76] & 274 COVID; 67 non-COVID & Plasma & $\begin{array}{l}\text { Hospital admission day } 0(\mathrm{~d} 0) \text {; } \\
\text { d03; d07; d14; d28; d84 }\end{array}$ & Untargeted LC-MS \\
\hline
\end{tabular}


Table 1: (continued)

\begin{tabular}{lllll}
\hline Author [ref.] & Patient cohort & $\begin{array}{l}\text { Biological } \\
\text { matrix }\end{array}$ & Time of sample collection & Method \\
\hline Doğan [78] & $\begin{array}{l}\text { 44 COVID; 41 healthy subjects (a discrep- } \\
\text { ancy on the number of participants is } \\
\text { evident between abstract and text) }\end{array}$ & Serum & $\begin{array}{l}\text { Morning after hospital admis- } \\
\text { sion; single timepoint collection }\end{array}$ & Untargeted LC-MS \\
Fraser [83] & $\begin{array}{l}\text { 10 COVID positive; 10 COVID negative; 10 } \\
\text { healthy subjects }\end{array}$ & Plasma & $\begin{array}{l}\text { ICU admission for up to 3 days } \\
\text { (COVID neg.) or 7 days (COVID } \\
\text { pos.) }\end{array}$ & Targeted ${ }^{1}$ H NMR spectroscopy \\
\hline
\end{tabular}

Table 2: Bioactive lipid mediators.

\begin{tabular}{|c|c|c|}
\hline Category & Function & Mediator \\
\hline Class 1 & $\begin{array}{l}\text { Members of this class are both useful to the virus and/or for the host by } \\
\text { - } \quad \text { amplification or reduction of inflammation } \\
-\quad \text { coordination of immune cell recruitment } \\
-\quad \text { cytokine and chemokine production } \\
-\quad \text { antibody formation } \\
-\quad \text { cell proliferation and migration } \\
-\quad \text { antigen presentation }\end{array}$ & $\begin{array}{l}\text { Eicosanoids (derived from arachidonic acid) } \\
-\quad \mathrm{PGE}_{2} \\
-\quad \mathrm{dmPGE}_{2} \\
-\quad \mathrm{dmPGA}_{1} \\
-\quad \mathrm{dmPGA}_{2} \\
-\quad \mathrm{LTE}_{4} \\
-\quad \mathrm{LTB}_{4}\end{array}$ \\
\hline Class 2 & $\begin{array}{l}\text { Members of this class (i.e., PAF, LPA, SP1) induce exclusively } \\
\text { a proviral environment by } \\
-\quad \text { enhancing viral replication } \\
-\quad \text { enhancing the inflammatory environment } \\
-\quad \text { increasing vascular permeability } \\
-\quad \text { promoting cytokines production }\end{array}$ & 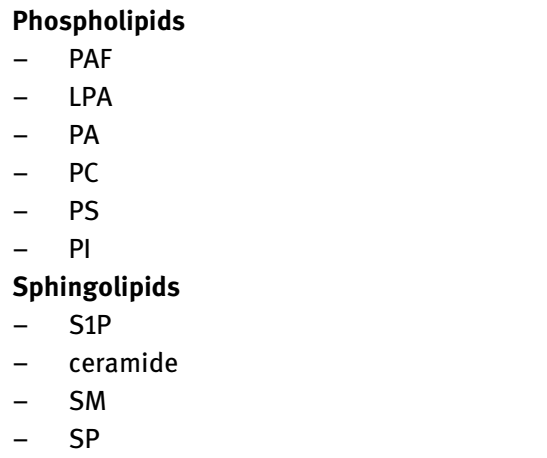 \\
\hline Class 3 & $\begin{array}{l}\text { Members of this class, (i.e., PD1, RvE1, lipoxin) have prohost activities } \\
\text { against viral infection by } \\
-\quad \text { blocking the acute inflammatory response } \\
-\quad \text { upregulating TNF- } \alpha \text { and IFN- } \gamma \\
-\quad \text { stimulating the recruitment of immune cells } \\
-\quad \text { decreasing NF-KB, AKT, ERK1/2, COX- } 2 \text { and } 5 \text {-lipoxygenase } \\
-\quad \text { modulating the proinflammatory class } 1 \text { lipid mediators }\end{array}$ & $\begin{array}{l}\omega-3 \text { fatty acids } \\
-\quad \text { protectins } \\
-\quad \text { resolvins } \\
-\quad \text { maresins } \\
\omega-6 \text { fatty acids } \\
-\quad \text { lipoxins (derived from arachidonic acid) }\end{array}$ \\
\hline
\end{tabular}

$P G E_{2}$, prostaglandin $E_{2} ; d m P G E_{2}$, dimethyl-prostaglandin $E_{2} ; d m P G A_{1}$, dimethyl-prostaglandin $A_{1} ; d m P G A_{2}$, dimethyl-prostaglandin $A_{2} ; L T E_{4}$, leukotriene $E_{4} ; L_{T B}$, leukotriene $B_{4} ; P A F$, platelet-activating factor; LPA, lysophosphatidic acid; PA, phosphatidic acid; PC, phosphocholine; PS, phosphatidylserine; PI, phosphatidylinositol; S1P, sphingosine-1-phosphate; SM, sphingomyelin; SP, sphingosine; PD1, protectin-1; RvE1,

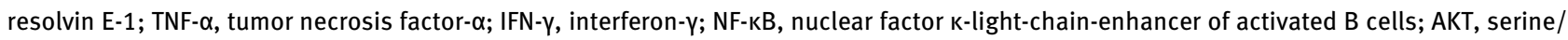
threonine kinase; ERK1/2, extracellular signal-regulated kinase 1/2; COX-2, cyclooxygenase-2. Mediator families have been written in bold.

mediators modulate inflammation and infection in critically ill patients [22]. Depending on the lipid class and the type of virus, bioactive lipid mediators play a dual role: on the one hand, they trigger the viral replication, the synthesis of proinflammatory factors (e.g., cytokines, chemokines) and the cell-cell fusion, inducing the so-called 'proviral environment'. On the other hand, lipid mediators boost the inhibition of viral replication, the synthesis of anti-inflammatory cytokines, and the macrophage differentiation, creating the so-called 'prohost environment'. Upon cell activation, lipid mediators are produced through specific biosynthetic pathways from the breakdown of various lipids either by oxidative fragmentation of polyunsaturated fatty acids or enzymatically, by phosphorylation/dephosphorylation of glycerophospholipids via phospholipases (PLs), phosphokinases, and phosphatases. Plasmalogens, special phospholipids with a vinyl ether moiety maintaining cell membrane integrity and involved in the immunomodulation, are of particular interest as a primary pool of polyunsaturated fatty acids (PUFAs) for the generation of lipid 
mediators. The biosynthesis of lipid mediators takes place within lipid droplets (LDs), small multifunctional organelles recognizable in all eukaryotic cells [23]; cholesteryl esters, triacylglycerols, and phospholipids are the main constituents. LDs were previously considered lipid storage organelles necessary to fuel intracellular metabolic pathways and membrane biosynthesis; currently, further key roles have emerged for LDs, including their preservative function against mitochondrial injury and lipotoxicity during autophagy [24]. Multiple evidences support the strong involvement of LDs both as platforms for viral replication [25] and key components in the intracellular host defense program, developed by innate immunity. Briefly, several pathogens promote the LDs biogenesis; concomitantly, the infected cell synthesizes antiviral citokines, predominantly IFNs, which in turn activate IFN-stimulated genes (ISGs) even localized within LDs (Figure 1). Thus, LDs are considered the first-line intracellular defense against SARS-CoV-2 and, more extensively, against several pathogens [26]. The in vitro infection of primary human monocytes, human lung epithelial cell line, and human lung microvascular endothelial cell line with SARS-CoV-2 has demonstrated that the virus triggers the increase of LDs within $24 \mathrm{~h}$ from the infection [27]. ISGs promote the synthesis of antiviral proteins, such as viperin, members of the immunity related GTPase family M proteins (IRGM), and members of the helicase family (Figure 1). In particular, SARS-CoV-2 infection promotes the reprogramming of monocytes towards lipogenesis, with the up-regulation of transcriptional lipogenic factors, such as CD36, sterol regulatory element-binding protein-1 (SREBP-1), peroxisome proliferator-activated receptor $y$ (PPARy), and diacylglycerol $o$-acyltransferase-1 (DGAT-1). As a result, LDs biogenesis is accelerated, leading to an increase of pro-inflammatory cytokines and chemokines. Further details have been reported in Figure 1.

Cholesterol plays multiple roles during viral entry, fusion between viral and host cell membranes, and viral replication. Recent evidences support the close interconnection between the aromatic residues in the helical portion of SARS-CoV-2 fusion peptide and membrane cholesterol; this association increases the binding affinity

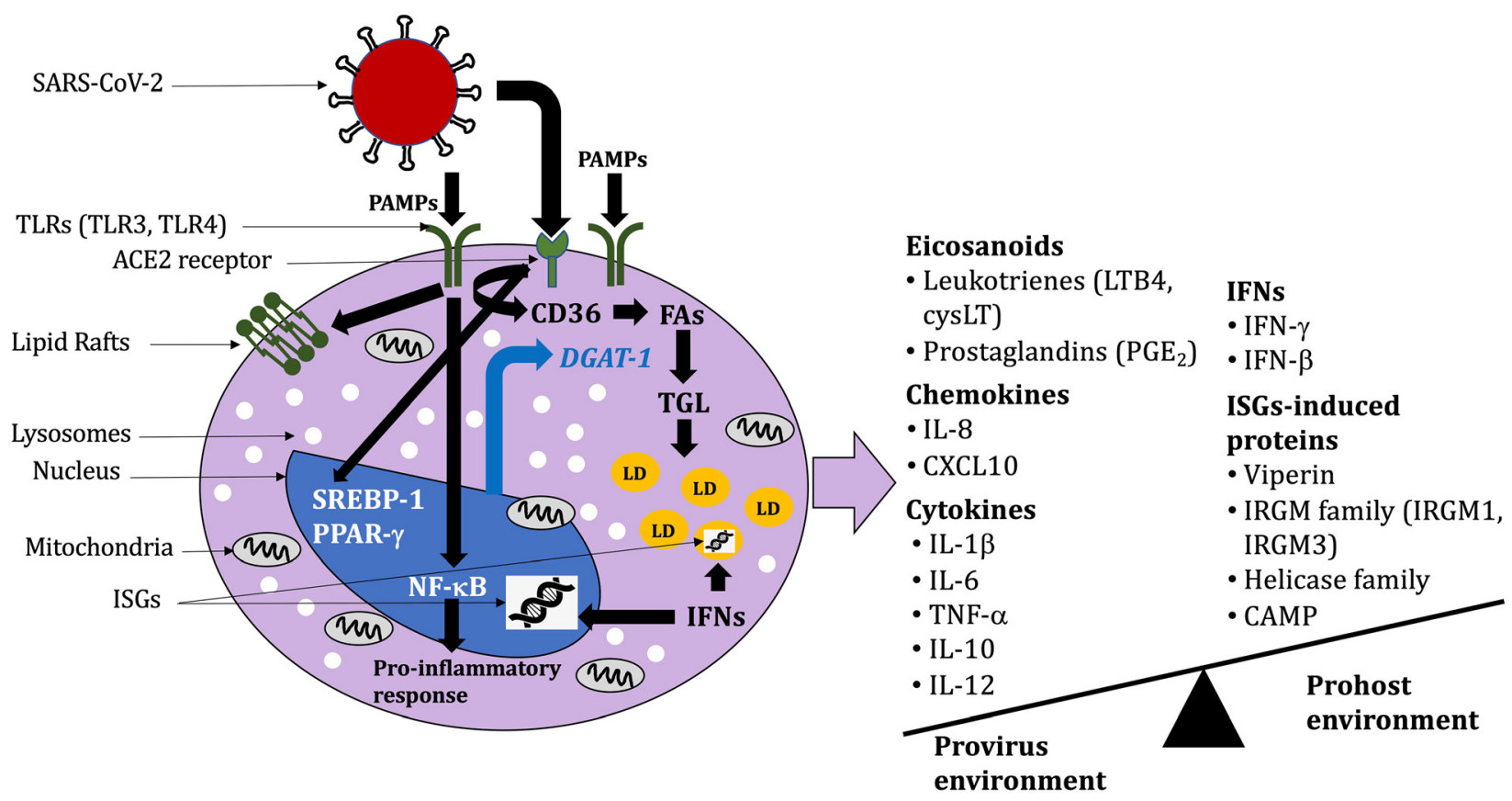

Figure 1: Partial representation of the lipid metabolic reprogramming induced both by SARS-CoV-2 infection and the response of the innate immunity within a monocyte.

SARS-CoV-2 entry promotes lipogenesis and the pro-inflammatory response by up-regulating several transcriptional factors, such as CD36, SERP-1, PPAR- $\gamma$, nuclear factor $\mathrm{k}$ light chain-enhancer of activated B cells (NF-kB), and the enzyme diacylglycerol $o$-acyltransferase 1 (DGAT1) catalyzing the final step of the triacylglycerol biosynthesis. Lipogenesis gives rise to lipid droplet (LD) biogenesis, which in turn, activate the synthesis of proinflammatory molecules, such as eicosanoids, chemokines, cytokines. SARS-CoV-2 could stimulate toll like receptors (TLRs) expression, especially TLR3 and TLR4. Activated TLRs are recruited into lipid rafts (LRs), participating in the cellular immune response. The binding between pathogen-associated molecular patterns (PAMP) and TLRs activates the NF-KB signaling and leads up to the expression of key proinflammatory cytokines. On the other hand, interferons (IFNs) downregulate cholesterol biosynthesis and upregulate the interferonstimulated genes (ISGs), recognizable not only within cellular nucleus, but also within LDs. As a result, several ISGs-induced proteins are overexpressed; viperin is the most important protein. 
and the subsequent fusion of the viral and host cell membranes [28]. Together with glycosphingolipids, phospholipids, and glycophosphatidylinositol (GPI)-linked proteins, cholesterol constitute lipid rafts, subdomains localized within the plasma membrane for receptor signaling events, including viral entry into host cells [29]. Lipid rafts recruit and concentrate various signaling molecules and operate as small-signal transduction platform; they are crucial for the interaction spike protein - ACE2 receptor, and for viral endocytosis [30]. High cholesterol levels positively correlate with the increase in lipid rafts, which in turn are closely associated with the ACE2-receptor. Collectively, data from the literature strongly support the importance of cholesterol for viral entry [31] and the need to lowering cholesterol levels for reducing viral infectivity [32]. The transcription factor SREBP-2 is highly expressed in severe COVID-19, suggesting a close relationship between the cholesterol biosynthesis and the pathogenesis of COVID-19 [33]. Intriguingly, SREBP-2 acts at multiple levels: it is also a transcription factor for inflammatory genes and sestrin-1 (SESN-1 or PA26). The latter inhibits the liver cholesterol biosynthesis by activating the AMP kinase pathway [34], while the SREBP-2 C-term fragment plays the same role as endotoxins, triggering cytokine storm in septic patients with COVID-19 [35]. The oxysterol 25 -hydroxycholesterol (25HC) is the product of the enzymatic oxidation of cholesterol by cholesterol 25 -hydrolase, an enzyme encoded by the ISG $\mathrm{CH} 25 \mathrm{H}$ [36]. The enzymatic activity of cholesterol 25-hydrolase promotes the internalization of $25 \mathrm{HC}$ in the late endosomes and the inhibition of cholesterol mobilization from the plasma membrane by activating the endoplasmic reticulum (ER)-localized acylCoA:cholesterol acyltransferase (ACAT) [37]. As a consequence, membrane fusion is inhibited [38].

Fatty acids are implied in the virus-host interplay; the essential free fatty acid linoleic acid binds to three binding pockets located in the receptor-binding domain (RBD) of the MERS-CoV and SARS-CoV-2 spike (S) glycoproteins and this binding inhibits the interactivity between linoleic acid and the host angiotensin-converting enzyme 2 (ACE2), facilitating the viral cell entry [39]. Arachidonic acid is a potent endogenous antiviral metabolite participating in the inactivation of enveloped viruses, including SARS-CoV-2 [40, 41]; cellular viral infection and inflammation promote the phospholipase $\mathrm{A}_{2}$-mediated cleavage of arachidonic acid from membrane phospholipids, especially in immunocompetent cells, such as macrophages, $\mathrm{T}$ and $\mathrm{B}$ cells, leading to the inactivation of the invading virus. The exogenous supplementation of arachidonic acid to infected cells significantly suppresses viral replication.
The mitochondrial long-chain fatty acids $\beta$-oxidation is impaired in SARS-CoV-2 infection [42] and other viral infections such as influenza and respiratory syncytial virus (RSV); $\beta$-oxidation defects are mirrored by changes in the concentration of long-chain acylcarnitines. The accumulation of long-chain acylcarnitines within the lung is a risk factor for developing acute lung injury due to their direct inhibition of the pulmonary surfactant [43].

Glycerophospholipids, commonly called phospholipids, their by-product lysophospholipids, and sphingolipids are key components of the cellular membrane and are involved in the metabolism of cell signaling. Glycerophospholipids are essential for the biosynthesis of lipoproteins; interestingly, glycerophospholipids mediate the first binding of the virus with the cell membrane, promoting the adhesion of SARS-CoV-2 and other viruses to the host cells [44]. Low plasma levels of glycerophospholipids may originate from the liver impairment in patients with severe COVID-19, while the overexpression of lysophospholipids suggests the increased activity of phospholipase $A_{2}$. Oxidized phospholipids (oxPLs), mainly generated by the nonenzymatic reaction between unsaturated fatty acids with reactive oxygen species (ROS), expand the host innate immune response and trigger the toll-like receptor 4 (TLR4) signaling pathway, contributing to the pathogenesis of acute lung injury; on the other hand, low levels of oxPLs improve the pulmonary endothelial barrier function and promote the expression of antioxidant genes, playing a protective role against viral replication and dissemination [18].

Among the prostaglandin (PG) family, $\mathrm{PGE}_{2}$ is crucial for viral replication, providing a proinflammatory environment; however, $\mathrm{PGE}_{2}$ enhances both the innate and adaptive immunity by modulating the activity of $\mathrm{T}$ cells [21]. Interestingly, pulmonary fibrosis following viral infection is promoted by prostaglandin $\mathrm{F}_{2 \alpha}\left(\mathrm{PGF}_{2 \alpha}\right)$ and restrained by prostacyclin $[45,46]$.

The complexity of the molecular mechanisms activated by the interplay between viral infection, inflammation, and lipid metabolism is reflected by two opposed (apparently) clinical features observed in patients with COVID-19. Briefly, two recent meta-analyses demonstrated that obesity, dyslipidemia, and metabolic syndrome in patients with SARS-CoV-2 infection are key risk factors for developing severe COVID-19 [47, 48]. A cascade reaction involving atherosclerotic plaques may at least partially explain the increased risk of developing severe COVID-19. High levels of low-density lipoproteins (LDLs) within the atherosclerotic plaques interact with macrophages, leading to an increase in inflammatory gene expression together with a concomitant increase of cytokines and chemokines; in turn, cytokines synthesis is induced by 
the adaptor protein myeloid differentiation factor 88 (MYD88)-mediated signaling via various TLRs, especially TLR2. Besides, the formation of cholesterol crystals within macrophages, due to LDLs accumulation, activates the inflammasome, promoting the secretion of proinflammatory cytokines. A further negative prognostic factor associated with dyslipidemia is endothelial dysfunction [49]; combining these factors is a powerful driver for the development of cardiovascular complications leading to severe clinical outcomes in COVID-19 patients. Differently, in normolipidemic subjects developing COVID-19, hypolipidemia occurs at the early stage of the disease and positively correlates with the severity of the disease; in particular, total serum cholesterol and its main fractions, LDL cholesterol, and high-density lipoprotein (HDL) cholesterol, are significantly decreased compared with those in healthy subjects [50]. An early study found high levels of triglycerides in patients with mild and severe COVID-19 but not in critical COVID-19 patients admitted in the intensive care unit (ICU) [51]. Several factors may induce hypolipidemia in COVID-19 patients, including liver injury due to SARS-CoV-2 hepatotoxicity, the role of proinflammatory cytokines, the lipid degradation by the leakage of free radicals from host cells infected by SARS-CoV-2, and the alteration of vascular permeability causing the cholesterol escape and its accumulation as exudate within alveolar spaces and other tissues. The drop of circulating cholesterol corresponds to severe cholesterol loading in peripheral tissue; this accumulation facilitates endocytosis, the most crucial entry pathway for SARS-CoV-2, increasing the viral infectivity.

\section{Lipidomics}

A couple of lipidomic studies investigated lipid alterations in various cell lines infected by Coronaviruses (CoVs). In the first study, the lipidomic profiling on Huh-7 (human liver cell line) and VeroE6 (kidney epithelial cells from an African green monkey) cells infected with human Coronavirus $229 \mathrm{E}$ (HCoV-229E) unveiled the up-regulation of lysophospholipids and FA synthesis together with perturbations of the linoleic acid - arachidonic acid metabolism [52]; in the second one, several cell lines infected with Middle East respiratory syndrome-related coronavirus (MERS-CoV) showed the up-regulation of lipogenesis, especially the pathway involved in the steroid biosynthesis [53]. In humans, COVID-19 severity and outcome are strongly influenced by the immune-regulatory and proinflammatory lipid mediators baseline level (before the onset of the disease) [54].
Triglycerides and triglycerides-rich lipoproteins (e.g., VLDL, LDL) are up-regulated in patients with COVID-19 [55-58]. This dysregulation is caused by the lipolysis of the adipose tissue, commonly observed in septic patients; the increase in triglycerides positively correlates both with the severity of the disease and fatal clinical outcome $[55,56]$, as opposed to results previously mentioned [51]. An additional source of triglycerides accumulation in patients with COVID-19 may be the excess of acetyl-CoA due to the reduction of its oxidation within the liver mitochondria [59]; as a consequence, acetyl-CoA oxidation is redirected to the synthesis of ketone bodies, leading to high levels of circulating acetoacetic acid, 3-hydroxybutyric acid, and acetone [58]. The biosynthetic pathway of arachidonic acid (C20:4), a polyunsaturated fatty acid, is significantly upregulated in patients with COVID-19 [54, 55, 60]. The elevation of arachidonic acid and other unsaturated fatty acids, such as oleic acid (C18:1) positively correlates with IL-6 concentration and with the severity of the disease [60]. However, a study reported the downregulation of fatty acids in patients with COVID-19, probably due to severe liver damage in patients' cohort, as stated by authors. This deduction was supported by the elevation of bile acids observed in those patients [61]. Specific saturated fatty acids, such as palmitic acid (C16:0) and stearic acid (C18:0), are significantly increased in patients with COVID-19 [55]. In the plasma of critical and noncritical patients with COVID-19, all the 18 acylcarnitines were found increased [55]; in severe and fatal COVID-19, serum concentrations of several short- and medium-chain acylcarnitines ( $\mathrm{C} 4, \mathrm{C} 4 \mathrm{OH}, \mathrm{C} 6, \mathrm{C} 8 \mathrm{OH}$ ) were elevated [62]. Interestingly, in the breast milk of COVID-19 puerperal women, isobutyrylcarnitine and butyrylcarnitine (C4) are increased [63]. Conversely, short- and long-chain acylcarnitines, except $\alpha$-linolenyl carnitine (C18:3), were found significantly decreased in the serum of patients with COVID-19 [60]; similarly, plasma C16, C18, and C18:1 long-chain acylcarnitines were decreased, suggesting the hypothesis of the slow entry of fatty acyls into mitochondria [64]. Some acylcarnitines, not better identified, were also found decreased in patients with severe COVID-19 marked by abnormal diffusing capacity of the lung for carbon monoxide [65]. The acylcarnitines shortage corresponds to the decrease of their anticoagulant function, enhancing the hypercoagulable phenotype associated with severe and fatal COVID-19 [66, 67]. COVID-19 and the severity of the disease strongly impact glycerophospholipids metabolism; most glycerophospholipids are downregulated in patients with COVID-19, while various lysophospholipids are overexpressed [54-56, 61, 64, 65, 68]. However, high levels of phosphatidylcholine (PC38:8), phosphatidylethanolamine 


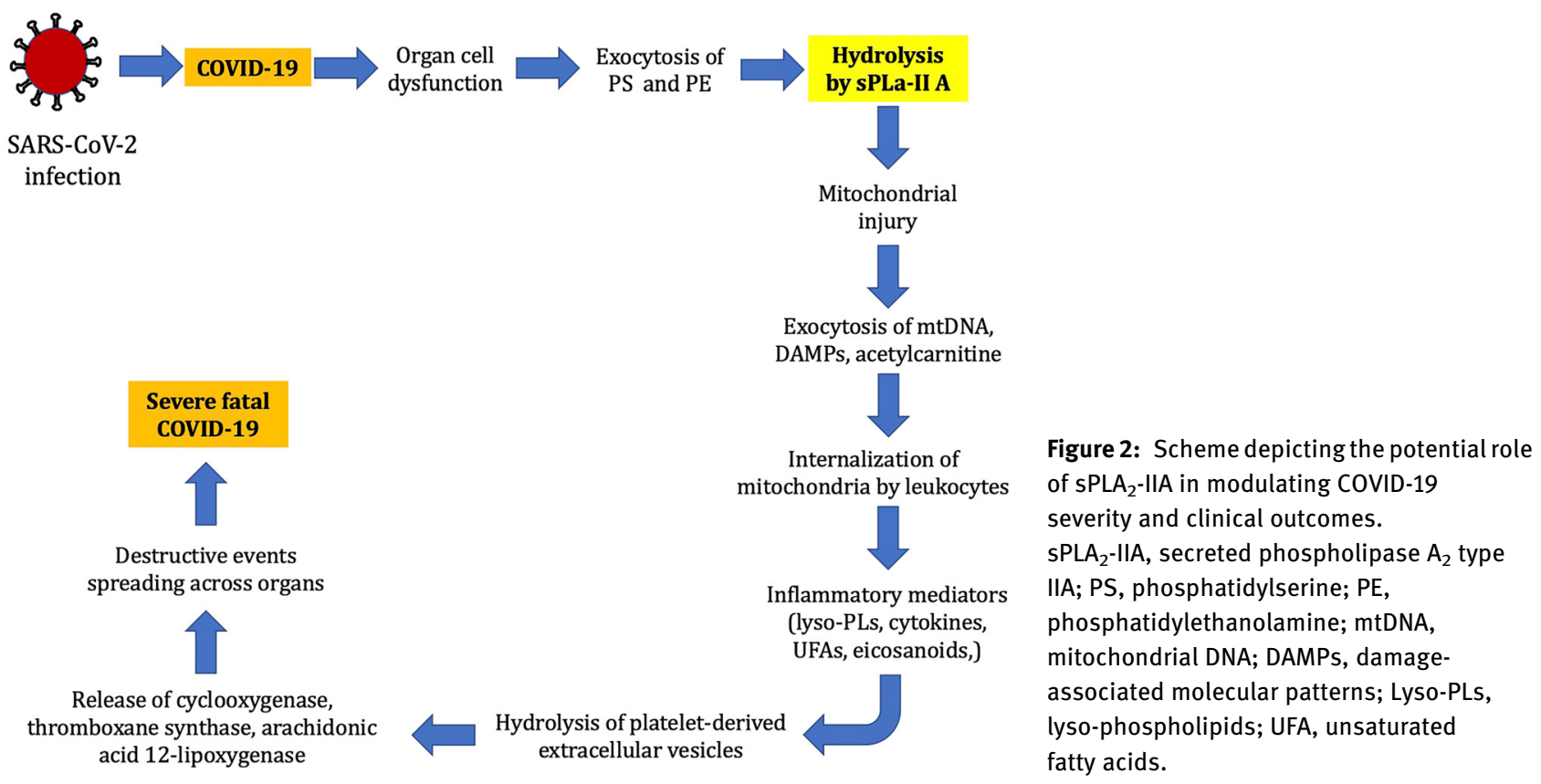

(PE38:4), and phosphatidylglycerol (PG20:5) discriminate low-risk infected patients from noninfected individuals [69]. Several sphingolipids, including sphingosine and sphingomyelins, have been found downregulated in COVID-19 [55, 61, 64, 69]; interestingly, by comparing severe with mild COVID-19, ceramides, as Cer(d18:0/20:0), Cer(d18:1/ 23:0), Cer(d18:1/18:0), Cer(d18:1/26:1), Cer(d18:0/26:10H) were found significantly increased and glycosylceramides, as HexCer(d16:1/22:0), Hex2Cer(d18:1/24:0), significantly decreased in severe patients [68]. Sphingosine 1-phosphate, a modulator of adaptive immune cell trafficking, vascular development, and homeostasis [70], was reduced in COVID-19 patients compared with healthy controls $[61,64]$. The underexpression of sphingosine 1-phosphate was associated with the predominance of inflammation over the macrophage-driven anti-inflammatory response. Conversely, it was observed that the increased activity of the red blood cells sphingosine kinase 1 (SPHK1), an enzyme catalyzing the phosphorylation of sphingosine to form sphingosine 1-phosphate in response to hypoxia, induces the increase of serum sphingosine 1-phosphate in COVID-19 patients [60]. By using machine learning models in patients with COVID-19, a research group observed that the secreted phospholipase $A_{2}$ type IIA (sPLA - IIA), a member of the secreted phospholipase $\mathrm{A}_{2}$ family, may mirror the severity of COVID-19 and predict the clinical outcome, being significantly different between survivors and non-survivors [71]. A significant positive correlation was observed between circulating SPLA2-IIA and various indices of disease severity, including hyperglycemia, kidney dysfunction, hypoxia, anemia, and multiple organ dysfunction. The sequence of molecular events promoted by SPLA $_{2}$-IIA in COVID-19 has been ordered in a scheme (Figure 2), highlighting their correlation with the severity and the clinical outcome of the disease. Structural and functional data on the lipids-virus interaction may open new perspectives on targeted therapeutic interventions to treat SARS-CoV-2 infection [72]. The most relevant result emerging from lipidomic studies may be considered a partial list of circulating lipids predisposing to a more severe and/or fatal COVID-19, as reported in Table 3. However, given the complexity of lipid classes and subclasses, results emerging from the literature are complex and partially ambiguous. Among glycerophospholipids, some phoshatidylcholines may result increased and others

Table 3: Circulating lipids predisposing to a more severe and/or fatal COVID-19.

\begin{tabular}{llr}
\hline Metabolite & Expression & Reference \\
\hline Triglycerides & Upregulated & {$[55],[56]$} \\
Arachidonic acid & Upregulated & {$[60]^{\mathrm{a}}$} \\
$\begin{array}{l}\text { Short- and medium-chain acylcarnitines: } \\
(\mathrm{C} 4, \mathrm{C} 4 \mathrm{OH}, \mathrm{C6}, \mathrm{C} 8 \mathrm{OH})\end{array}$ & {$[62]$} \\
$\begin{array}{l}\text { Ceramides: Cer(d18:0/20:0), } \\
\text { Cer(d18:1/23:0), Cer(d18:1/18:0), }\end{array}$ & Upregulated & {$[68]$} \\
$\begin{array}{l}\text { Cer(d18:1/26:1), Cer(d18:0/26:10H) } \\
\text { Glycosylceramides: HexCer(d16:1/22:0), }\end{array}$ & Downregulated & {$[68]$} \\
$\begin{array}{l}\text { Hex2Cer(d18:1/24:0) } \\
\text { Secreted phospholipase } \mathrm{A}_{2} \text { type IIA } \\
(\mathrm{sPLA}-\text { IIA) }\end{array}$ & Upregulated & {$[71]$} \\
\hline
\end{tabular}

${ }^{\mathrm{a}}$ In patients with severe liver damage, arachidonic acid was found downregulated, independently from the disease severity [61]. 
decreased in the same group of patients; more important, differences between studies may originate controversial results on a single metabolite. Variables, such as the biological matrix, analytical platforms, internal standards, and libraries for human lipidome, lead to the identification of different lipidomic profiles discriminating critical from noncritical patients and infected from noninfected individuals. Accordingly, metanalyses on lipidomic datasets in COVID-19 seem to be premature and their conclusions may be questionable and, at least partially, inconclusive [73].

\section{Amino acids metabolism in patients with COVID-19}

COVID-19 is characterized by the strong activation of gluconeogenesis; hence, most gluconeogenic amino acids, including valine, alanine, glycine, serine, histidine, glutamine, and methionine, are significantly decreased [54, 58, 61, 74-76]. The decrease of gluconeogenic amino acids is inversely correlated with the disease's severity, as demonstrated by the significant inverse correlation with IL-6 level [60]. In COVID-19, hypoxia plays a crucial role in altering the TCA cycle intermediates and related pathways; on the one hand, hypoxia inhibits the malate-aspartate shuttle, inducing the consistent decrease of aspartate and perturbations in the alanine-aspartate-glutamate pathway [77]. Furthermore, hypoxia promotes the intensification of succinate synthesis, resulting in the depletion of various metabolites, such as fumarate [55, 61, 64], malate and aspartate [56], $\alpha$-ketoglutarate [61], and glutamate [61, 78]. Oddly, glutamate was found increased in two studies $[58,75]$; however, they did not report any data on glutamine, preventing any plausible conclusion. Nevertheless, the decrease of the glutamine/glutamate in COVID-19 is considered clinically useful, reflecting the metabolic reprogramming of energy metabolism, the increased skeletal muscle catabolism, liver failure, and septic shock [78]. Notably, emerging knowledge on the putative metabolic reprograming of glutamine in host cells upon SARS-CoV-2 infection boosts the research of glutamine metabolismrelated therapeutic drugs [79]. Even results on succinate are ambiguous; it was found increased [55, 58], decreased [64], or unchanged [60]. The increase of succinate reflects hypoxia; it is reasonable to assume that in studies reporting decreased or unchanged levels of succinate, patients with COVID-19 were normo-oxygenate or undergoing intense respiratory treatment. Malate exerts a protective effect on the endothelium of the blood vessels, and the lack of this amino acid increases the risk of endothelial injury $[80,81]$.
Low levels of malate result in decreased levels of aspartate. Aspartate is involved in the TCA cycle and in the arginine, glycine-serine-threonine metabolism; even purine metabolism and de novo pyrimidine biosynthesis depend on aspartate availability. The decrease of aspartate is probably due to a deficiency of electron acceptors necessary for aspartate synthesis by the TCA cycle [82]. Perturbations in the arginine metabolism were observed in patients with COVID-19 [60-62, 65, 74, 83]. L-arginine, a conditionally essential amino acid derived from proteolysis and food intake, is the precursor of the endothelium-derived relaxing factor nitric oxide (NO) and is involved in the synthesis of urea, L-ornithine, L-proline, polyamines, and creatine [84]. L-arginine decarboxylation originates agmatine, a neuromodulator found altered in major diseases of the central nervous system [85]. Moreover, L-arginine is strongly implied in the host immune response, especially by modulating signal transduction pathways in immune cells [86, 87] and regulating the T-cells metabolism, such as glycolysis and mitochondrial activity [88]. Both sepsis and septic shock induces the lack of arginine availability by at least three mechanisms: enhanced consumption, with the considerable contribution of the cytokines-induced increase of the nitric oxide synthase (EC 1.14.13.39) activity; reduced de novo synthesis; decreased nutritional intake [89]. L-arginine deficiency significantly reduces the resistance to infections, since in activated macrophages NO synthesis is essential for host defense against pathogens. Only three metabolomics-based studies found reduced levels of L-arginine and/or intermediates and end-products in patients with COVID-19 [61, 62, 83]; these findings have been associated with liver dysfunction [56]. The depletion rate of L-arginine positively correlates with the severity of the disease and the length of patient's stay in ICU [83], according to the notion that this amino acid is basic for tissue repair [90]. In patients with moderate and high IL-6 levels, L-arginine was found increased and associated with the decrease of the urea cycle metabolic intermediates ornithine and citrulline and with the increase of creatine, spermidine, and acetyl-spermidine; this finding suggests that the impaired kidney function in patients with COVID-19 may be the main factor inducing this complex association [60]. The increase of L-arginine in COVID-19 was also explained by airway remodeling [65]. In the paper of Blasco et al. the discriminant multivariate model predicting the diagnosis of SARS-CoV-2 included L-arginine within the top-10 significant metabolites, reported in Figure 2 of that study; regrettably, no information is available either on the increase or the decrease of this amino acid [74].

Tryptophan metabolism, including the kynurenine and the nicotinamide pathways, is strongly altered in 
patients with COVID-19 and many studies reported a significant decrease of tryptophan in conjunction with a significant increase of kynurenine and kynurenic acid $[55,57,60-62,64,74,75,83]$. These trends were positively correlated with disease's severity and fatal clinical outcome [57, 62]. The decrease of tryptophan is inversely correlated with serum levels of IL-6 [60] and cortisol [62]. These data suggest a close relationship between the immune response to SARS-CoV-2 and the tryptophan metabolism; the ultimate objective is to boost the energyproducing cofactor NAD. Hypercortisolemia is associated with higher mortality in patients with COVID-19 [91] and upregulates tryptophan 2, 3-dioxygenase (EC 1.13.11.11), an enzyme encoded by the TDO2 gene catalyzing the oxidation of tryptophan to kynurenine. The upregulation of the tryptophan degradation to kynurenine and kynurenic acid promotes two further metabolic dysregulations; from the one hand, the reduced conversion of tryptophan to serotonin results in serotonin and melatonin deficiency [62], even though 5-hydroxytryptophan, the precursor of serotonin, is increased in COVID-19 patients [64]. On the other hand, the increased availability of quinolinic acid, originating from the transformation of kynurenine to 3-hydroxyanthranilic acid, leads to high levels of nicotinamide [62, 74] and nicotinic acid [60], both positively correlated with COVID-19 severity and fatal outcome [62, 92]. It was postulated that the kynurenine pathway's hyperactivation facilitates SARS-CoV-2 to circumvent the host immune response [60]. Perturbations in the kynurenine pathway alter the kynurenine/tryptophan ratio; several studies observed a significant increase of this ratio in SARS-CoV-2 infected patients [57, 61, 62, 92]. The kynurenine/tryptophan ratio may be considered an indirect measurement of the enzymatic activity of indole 2, 3-dioxygenase (IDO) [60, 62, 75], a pleiotropic enzyme involved in modulating the immune response. IDO promotes the conversion of tryptophan to kynurenine, which activates the aryl hydrocarbon receptor [93]. Thus, IDO controls and limits pulmonary inflammation, improving survival from COVID-19 in critically ill patients. In order to identify emerging diagnostic and prognostic biomarkers for COVID-19, a study performed on a small patient cohort found that using a cut-off level of 15.7, the arginine/ kynurenine ratio discriminated COVID-19 patient from healthy subjects with $100 \%$ diagnostic accuracy and COVID positive from COVID negative patients with 98\% diagnostic accuracy [83]. In addition, the creatinine/arginine ratio predicted death in patients admitted to ICU with $100 \%$ diagnostic accuracy. However, before being definitively accepted and proposed as clinical tests, these results must be replicated and validated on larger patient cohorts.
COVID-19 alters the biosynthesis and metabolism of phenylalanine and tyrosine [55, 58, 60, 75]; indeed, it has long been known that the accumulation of phenylalanine occurs during an infection- or sepsis-induced inflammation $[94,95]$. Multiple factors associated with the infection and the related immune stimulation may contribute to the accumulation of phenylalanine; the most important mechanism is the progressive unavailability of $5,6,7$, 8-tetrahydrobiopterin (BH4), a reduced form of biopterin. BH4, a hydrogen donor, is a cofactor of phenylalanine 4-hydroxylase (EC 1.14.13.39; PAH), the enzyme catalyzing the conversion of phenylalanine to tyrosine. Cytokine activation in response to infections and sepsis triggers the formation of reactive oxygen species (ROS), which promote the irreversible non-enzymatic oxidation of $\mathrm{BH} 4$ to 7, 8-dihydrobiopterin (BH2). The consequent shortage of BH4 induces the loss of PAH activity, with the reduced conversion of phenylalanine to tyrosine (Figure 3). Even the enzymatic conversion of tyrosine to L-DOPA, catalyzed by the tyrosine 5-hydrolase, is dependent on BH4; as a result, large amounts of ROS hamper the biosynthesis of tyrosine, dopamine, norepinephrine, and epinephrine. Data emerging from metabolomic studies in patients with COVID-19 are discordant: both phenylalanine and tyrosine were found decreased [55] or increased [75]; a study reported the increase of phenylalanine in conjunction with the decrease of tyrosine [58], and one more study reported no information on phenylalanine and tyrosine levels [60]. Variables, such as the severity of COVID-19, the therapeutic treatment, the severity of liver failure (the hydroxylation of phenylalanine to tyrosine occurs mainly in the liver), and the presence of co-morbidities may influence results.

\section{The system biology approach to SARS-CoV-2 infection}

Efforts to investigate the molecular mechanisms associated with SARS-CoV-2 infection in asymptomatic individuals and patients developing COVID-19 have involved multi-omics approaches, including metabolomics and microbiomics. This strategy can address multiple goals, including to predicting which patients with COVID-19 are at high risk of severe lung function impairment, multiple organ failure, death, and which patients will respond effectively to the therapeutic treatment [92]. Pharmaceutical industries and academic research institutes are strongly involved in investigating and interpreting the host metabolic response to SARS-CoV-2 vaccines and related mechanisms underlying the individual variability in vaccine response. One crucial question that metabolomics may address is whether 


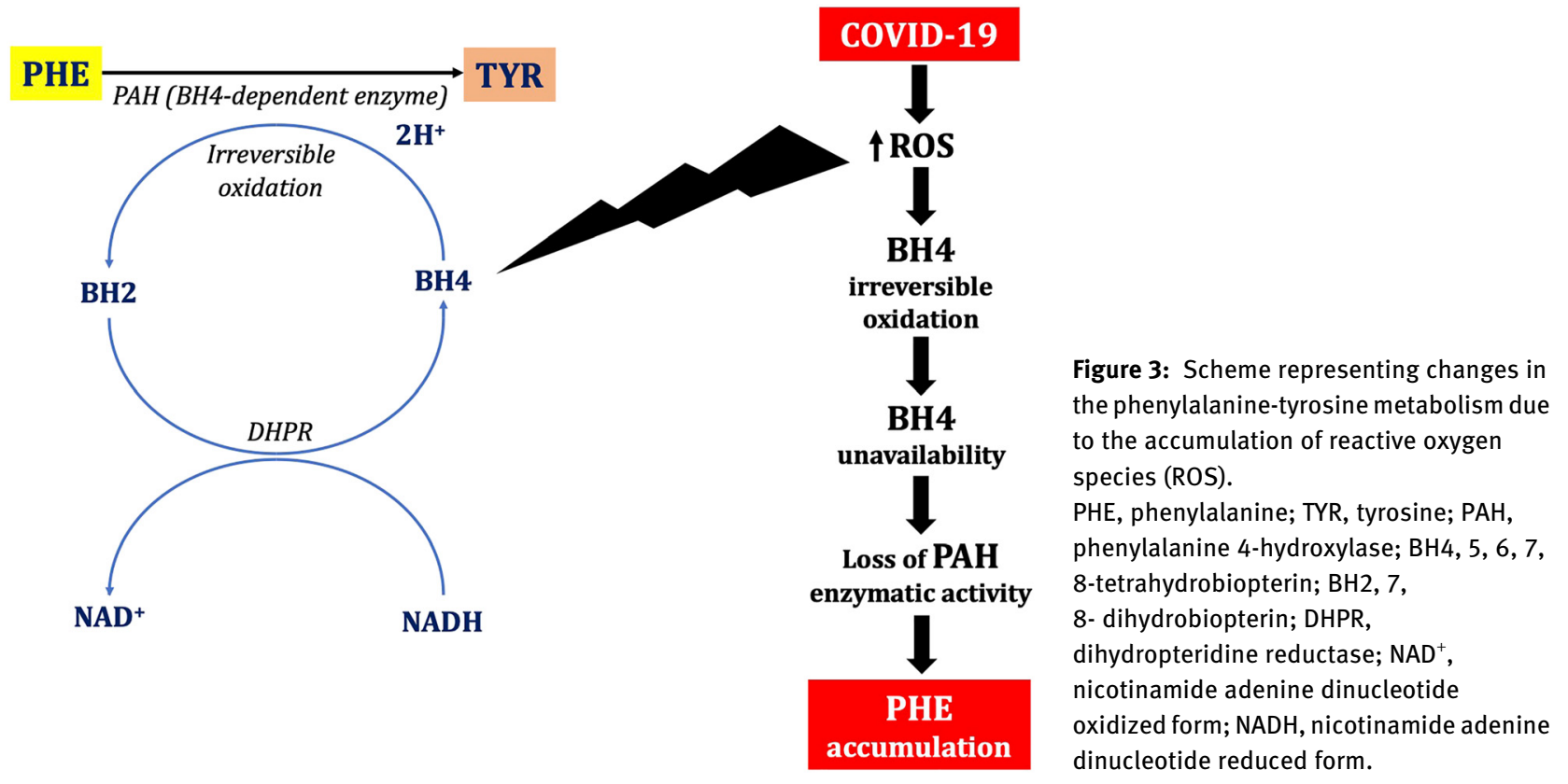

and how endogenous nucleotide metabolism affects the response to DNA/RNA-based vaccines via replicative efficacy. Emerging knowledge on the ability of SARS-CoV-2 to induce gut dysbiosis by infecting and replicating in human small intestine enterocytes call for the proper understanding and interpretation of microbiomics and metabolomics data; indeed, evidence suggests that gut dysbiosis modulates host immune response, being positively correlated with plasma concentrations of several inflammatory biomarkers (cytokines, chemokines, acute-phase reactants) and with COVID-19 severity and outcomes [96]. Gut microbiota co-metabolites, such as the short-chain fatty acid (SCFA) palmitic acid, originating from gut microbial fermentation of dietary fiber, promote the immune response to the SARS-CoV-2 at distal sites, especially the lungs, and influence the host inflammatory response in patients with COVID-19 [97].

\section{Conclusive and prospective remarks}

Human SARS-CoV-2 infection activates a complex interaction host/virus forming the basis of a wide range of outcomes, from the asymptomatic infection to life-threatening acute respiratory distress syndrome (ARDS), vascular dysfunction, and sepsis. Two steps are crucial for the viral infection's fate: (a) the direct interaction between the coronavirus spike protein with the host cell surface receptor and many other cell surface molecules facilitating virus attachment or entry; (b) the exploitation of host cell machinery for viral replication and spread. Molecular and metabolic alterations resulting from these two steps form the basis of the individual susceptibility to the onset of COVID-19. Thus, there is the need to speeding up the transition of metabolomics from clinical research into clinical testing, considering that the measurement of a restricted number of metabolites may become feasible and cheap for clinical laboratories that already use LC-MS for testing steroid hormones and immunosuppressive drugs [98]. Three simple ratios based on metabolomic data might be rapidly introduced in the routine practice: the kynurenine/ tryptophan ratio, the glutamine/glutamate ratio, and the Fischer's ratio (valine + leucine + isoleucine)/(phenylalanine + tyrosine), also known as BCAA/aromatic amino acids ratio. The Fischer's ratio is well known for a long time [99] and its significantly decrease in COVID-19 represents an accurate index of liver dysfunction [75]. Furthermore, recent experimental findings on type II pneumocytes of lung from infected patients and in cultured cells have demonstrated the peculiar changes in lipid metabolism and LDs biogenesis induced by SARS-CoV-2; these results may open new perspectives to effectively neutralize the SARS-CoV-2 pathogenicity [100]. Some severe limitations affect most metabolomics-based studies on COVID-19, slowing the routine application of metabolomics. For example, the right interpretation of changes in serum succinate level needs detailed patient's clinical data, including the blood oxygenation and the intensity and duration of respiratory treatment. By this way is possible to identify factors influencing the depletion of succinate in patients 
with COVID-19, as observed elsewhere [64]. Moreover, in the study evaluating the diagnostic accuracy of the arginine/kynurenine ratio, authors highlighted the urgent need to develop lateral flow immunochromatographic assays for the near-patient metabolomic testing [83]. This claim sounds inopportune, especially at state of the art. Moving metabolomics from bench to bedside cannot imply the mere determination of a given metabolite panel by nonreliable and non-standardized methods; rather, slotting metabolomics into clinical practice takes much more than any available point-of-care testing including the conversion of metabolic patient-specific data into actionable clinical applications [101]. Finally, the analysis and interpretation of metabolomic data should be integrated with other biological and imaging data; hence, the contribution of artificial intelligence and machine learning algorithms may considerably improve the effective utilization of results for clinical decision making.

Research funding: None declared.

Author contributions: All authors have accepted responsibility for the entire content of this manuscript and approved its submission.

Competing interests: Authors state no conflict of interest. Informed consent: Not applicable.

Ethical approval: Not applicable.

\section{References}

1. Thaker SK, Ch'ng J, Christofk HR. Viral hijacking of cellular metabolism. BMC Biol 2019;17:59.

2. Buck MD, O'Sullivan D, Pearce EL. T cell metabolism drives immunity. J Exp Med 2015;212:1345-60.

3. Rodriguez AE, Ducker GS, Billingham LK, Martinez CA, Mainolfi N, Suri V, et al. Serine metabolism supports macrophage IL-1 $\beta$ production. Cell Metabol 2019;29:1003-11. e4.

4. Capobianchi MR, Uleri E, Caglioti C, Dolei A. Type I IFN family members: similarity, differences and interaction. Cytokine Growth Factor Rev 2015;26:103-11.

5. Stanifer ML, Guo C, Doldan P, Boulant S. Importance of type I and III interferons at respiratory and intestinal barrier surfaces. Front Immunol 2020;11:608645.

6. Hadjadj J, Yatim N, Barnabei L, Corneau A, Boussier J, Smith N, et al. Impaired type I interferon activity and inflammatory responses in severe COVID-19 patients. Science 2020;369: 718-24.

7. Ashrafian H, Sounderajah V, Glen R, Ebbels T, Blaise BJ, Kalra D, et al. Metabolomics - the stethoscope for the 21st century. Med Princ Pract 2020:1-10. https://doi.org/10.1159/000513545. [Online ahead of print].

8. Costa Dos Santos Junior G, Pereira CM, Kelly da Silva Fidalgo T, Valente AP. Saliva NMR-based metabolomics in the war against COVID-19. Anal Chem 2020;92:15688-692.
9. Brann DH, Tsukahara T, Weinreb C, Lipovsek M, Van den Berge $\mathrm{K}$, Gong B, et al. Non-neuronal expression of SARS-CoV-2 entry genes in the olfactory system suggests mechanisms underlying COVID-19-associated anosmia. Sci Adv 2020;6: eabc5801.

10. Mounayar R, Morzel M, Brignot $\mathrm{H}$, Tremblay-Franco M, Canlet C, Lucchi G, et al. Salivary markers of taste sensitivity to oleic acid: a combined proteomics and metabolomics approach.

Metabolomics 2014;10:688-96.

11. Mounayar R, Morzel M, Brignot H, Tremblay-Franco M, Canlet C, Lucchi G, et al. Nutri-metabolomics applied to taste perception phenotype: human subjects with high and low sensitivity to taste of fat differ in salivary response to oleic acid. OMICS 2014;18: 666-72.

12. Ogawa T, Hoshina K, Haginaka J, Honda C, Tanimoto T, Uchida T. Screening of bitterness-suppressing agents for quinine: the use of molecularly imprinted polymers. J Pharmacol Sci 2005;94: 353-62.

13. Sapkota D, Søland TM, Galtung HK, Sand LP, Giannecchini S, To KKW, et al. COVID-19 salivary signature: diagnostic and research opportunities. J Clin Pathol 2020:1-6. https://doi.org/ 10.1136/jclinpath-2020-206834.

14. Kang JH, Kho HS. Blood contamination in salivary diagnostics: current methods and their limitations. Clin Chem Lab Med 2019; 57:1115-24.

15. Brogna R, Oldenhof H, Sieme H, Wolkers WF. Spectral fingerprinting to evaluate effects of storage conditions on biomolecular structure of filter-dried saliva samples and recovered DNA. Sci Rep 2020;10:21442.

16. Henning A. Proton and multinuclear magnetic resonance spectroscopy in the human brain at ultra-high field strength: a review. Neuroimage 2018;168:181-98.

17. Bellagambi FG, Lomonaco T, Salvo P, Vivaldi F, Hangouet M, Ghimenti S, et al. Saliva sampling: methods and devices. An overview. Trends Anal Chem 2020;124: 115781.

18. Theken KN, FitzGerald GA. Bioactive lipids in antiviral immunity. Science 2021;371:237-8.

19. Pidgeon C, Markovich RJ, Liu MD, Holzer TJ, Novak RM, Keyer KA. Antiviral phospholipids. Anti-HIV drugs conjugated to the glycerobackbone of phospholipids. J Biol Chem 1993;268: 7773-78.

20. Casari I, Manfredi M, Metharom P, Falasca M. Dissecting lipid metabolism alterations in SARS-CoV-2. Prog Lipid Res 2021;82: 101092.

21. Monson EA, Trenerry AM, Laws JL, Mackenzie JM, Helbig KJ. Lipid droplets and lipid mediators in viral infection and immunity. FEMS Microbiol Rev 2021:1-20. fuaa066. https://doi.org/10. 1093/femsre/fuaa066.

22. Cioccari L, Luethi N, Masoodi M. Lipid mediators in critically ill patients: a step towards precision medicine. Front Immunol 2020;11: 599853.

23. Lundquist PK, Shivaiah KK, Espinoza-Corral R. Lipid droplets throughout the evolutionary tree. Prog Lipid Res 2020;78: 101029.

24. Nguyen TB, Olzmann JA. Lipid droplets and lipotoxicity during autophagy. Autophagy 2017;13:2002-3.

25. Pagliari F, Marafioti MG, Genard G, Candeloro P, Viglietto G, Seco J, et al. SSRNA virus and host lipid rearrangements: is there a role for lipid droplets in SARS-CoV-2 infection? Front Mol Biosci 2020;7: 578964. 
26. Bosch M, Sánchez-Álvarez M, Fajardo A, Kapetanovic R, Steiner B, Dutra F, et al. Mammalian lipid droplets are innate immune hubs integrating cell metabolism and host defense. Science 2020;370: eaay8085.

27. Dias SSG, Soares VC, Ferreira AC, Sacramento CQ, FintelmanRodrigues N, Temerozo JR, et al. Lipid droplets fuel SARS-CoV-2 replication and production of inflammatory mediators. PLoS Pathog 2020;16: e1009127.

28. Gorgun D, Lihan M, Kapoor K, Tajkhorshid E. Binding mode of SARS-CoV-2 fusion peptide to human cellular membrane. Biophys J 2021;S0006-3495:00199-5.

29. Regen SL. The origin of lipid rafts. Biochemistry 2020;59: 4617-21.

30. Fecchi K, Anticoli S, Peruzzu D, lessi E, Gagliardi MC, Matarrese P, et al. Coronavirus interplay with lipid rafts and autophagy unveils promising therapeutic targets. Front Microbiol 2020;11:1821.

31. Sanders DW, Jumper CC, Ackerman PJ, Bracha D, Donlic A, Kim H, et al. SARS-CoV-2 requires cholesterol for viral entry and pathological syncytia formation. Elife 2021;10:e65962.

32. Radenkovic D, Chawla S, Pirro M, Sahebkar A, Banach M. Cholesterol in relation to COVID-19: should we care about it? J Clin Med 2020;9:1909.

33. Toelzer C, Gupta K, Yadav SKN, Borucu U, Davidson AD, Kavanagh Williamson $M$, et al. Free fatty acid binding pocket in the locked structure of SARS-CoV-2 spike protein. Science 2020, 370:725-30.

34. Lee W, Ahn JH, Park HH, Kim HN, Kim H, Yoo Y, et al. COVID19-activated SREBP2 disturbs cholesterol biosynthesis and leads to cytokine storm. Signal Transduction Targeted Ther 2020;5:186.

35. Li Z, Votava JA, Zajac GJM, Nguyen JN, Leyva Jaimes FB, Ly SM, et al. Integrating mouse and human genetic data to move beyond GWAS and identify causal genes in cholesterol metabolism. Cell Metabol 2020;31:741-54. e5.

36. Sohrabi Y, Reinecke H, Godfrey R. Altered cholesterol and lipid synthesis mediates hyperinflammation in COVID-19. Trends Endocrinol Metabol 2021;32:132-4.

37. Zu S, Deng YQ, Zhou C, Li J, Li L, Chen Q, et al. 25 -Hydroxycholesterol is a potent SARS-CoV-2 inhibitor. Cell Res 2020;30:1043-5

38. Wang S, Li W, Hui H, Tiwari SK, Zhang Q, Croker BA, et al. Cholesterol 25-Hydroxylase inhibits SARS-CoV-2 and other coronaviruses by depleting membrane cholesterol. EMBO J 2020; 39: e106057.

39. Zang R, Case JB, Yutuc E, Ma X, Shen S, Gomez Castro MF, et al. Cholesterol 25-hydroxylase suppresses SARS-CoV-2 replication by blocking membrane fusion. Proc Natl Acad Sci U S A 2020;117: 32105-113.

40. Das UN. Arachidonic acid and other unsaturated fatty acids and some of their metabolites function as endogenous antimicrobial molecules: a review. J Adv Res 2018;11:57-66.

41. Hoxha M. What about COVID-19 and arachidonic acid pathway? Eur J Clin Pharmacol 2020;76:1501-4.

42. Ayres JS. A metabolic handbook for the COVID-19 pandemic. Nat Metab 2020;2:572-85.

43. Otsubo C, Bharathi S, Uppala R, Ilkayeva OR, Wang D, McHugh K, et al. Long-chain acylcarnitines reduce lung function by inhibiting pulmonary surfactant. J Biol Chem 2015;290:23897-904.

44. Mazzon M, Marsh M. Targeting viral entry as a strategy for broadspectrum antivirals. F1000Res. 2019;8:F1000 Faculty Rev-1628.
45. Oga T, Matsuoka T, Yao C, Nonomura K, Kitaoka S, Sakata D, et al. Prostaglandin F(2alpha) receptor signaling facilitates bleomycininduced pulmonary fibrosis independently of transforming growth factor-beta. Nat Med 2009;15:1426-30.

46. Lovgren AK, Jania LA, Hartney JM, Parsons KK, Audoly LP, Fitzgerald GA, et al. COX-2-derived prostacyclin protects against bleomycin-induced pulmonary fibrosis. Am J Physiol Lung Cell Mol Physiol 2006;291:L144-56.

47. Popkin BM, Du S, Green WD, Beck MA, Algaith T, Herbst CH, et al. Individuals with obesity and COVID-19: a global perspective on the epidemiology and biological relationships. Obes Rev 2020; 21:e13128.

48. Hariyanto TI, Kurniawan A. Dyslipidemia is associated with severe coronavirus disease 2019 (COVID-19) infection. Diabetes Metab Syndr 2020;14:1463-65.

49. Froldi G, Dorigo P. Endothelial dysfunction in Coronavirus disease 2019 (COVID-19): gender and age influences. Med Hypotheses 2020;144:110015.

50. Hu X, Chen D, Wu L, He G, Ye W. Declined serum high density lipoprotein cholesterol is associated with the severity of COVID-19 infection. Clin Chim Acta 2020;510:105-10.

51. Wei X, Zeng W, Su J, Wan H, Yu X, Cao X, et al. Hypolipidemia is associated with the severity of COVID-19. J Clin Lipidol 2020;14: 297-304.

52. Yan B, Chu H, Yang D, Sze KH, Lai PM, Yuan S, et al. Characterization of the lipidomic profile of human coronavirusinfected cells: implications for lipid metabolism remodeling upon coronavirus replication. Viruses 2019;11:73.

53. Yuan S, Chu H, Chan JF, Ye ZW, Wen L, Yan B, et al. SREBP-dependent lipidomic reprogramming as a broadspectrum antiviral target. Nat Commun 2019;10:120.

54. Schwarz B, Sharma L, Roberts L, Peng X, Bermejo S, Leighton I, et al. Cutting edge: severe SARS-CoV-2 infection in humans is defined by a shift in the serum lipidome, resulting in dysregulation of eicosanoid immune mediators. J Immunol 2021; 206:329-34.

55. Barberis E, Timo S, Amede E, Vanella VV, Puricelli C, Cappellano $\mathrm{G}$, et al. Large-scale plasma analysis revealed new mechanisms and molecules associated with the host response to SARS-CoV-2. Int J Mol Sci 2020;21:8623.

56. Wu D, Shu T, Yang X, Song J-X, Zhang M, Yao C, et al. Plasma metabolomic and lipidomic alterations associated with COVID-19. Natl Sci Rev 2020;7:1157-68.

57. Overmyer KA, Shishkova E, Miller IJ, Balnis J, Bernstein MN, Peters-Clarke TM, et al. Large-scale multi-omic analysis of COVID-19 severity. Cell Syst 2021;12:23-40. e7.

58. Bruzzone C, Bizkarguenaga M, Gil-Redondo R, Diercks T, Arana E, García de Vicuña A, et al. SARS-CoV-2 infection dysregulates the metabolomic and lipidomic profiles of serum. iScience 2020;23: 101645.

59. Fierro NA. COVID-19 and the liver: what do we know after six months of the pandemic? Ann Hepatol 2020;19:590-91.

60. Thomas T, Stefanoni D, Reisz JA, Nemkov T, Bertolone L, Francis RO, et al. COVID-19 infection alters kynurenine and fatty acid metabolism, correlating with IL- 6 levels and renal status. JCI Insight 2020;5: e140327.

61. Shen B, Yi X, Sun Y, Bi X, Du J, Zhang C, et al. Proteomic and metabolomic characterization of COVID-19 patient sera. Cell 2020;182:59-72. e15. 
62. Roberts I, Wright Muelas M, Taylor JM, Davison AS, Xu Y, Grixti JM, et al. Untargeted metabolomics of COVID-19 patient serum reveals potential prognostic markers of both severity and outcome. MedRxiv [Preprint] 2020;1-32.

63. Zhao Y, Shang Y, Ren Y, Bie Y, Qiu Y, Yuan Y, et al. Omics study reveals abnormal alterations of breastmilk proteins and metabolites in puerperant women with COVID-19. Signal Transduction Targeted Ther 2020;5:247.

64. Song JW, Lam SM, Fan X, Cao WJ, Wang SY, Tian H, et al. Omicsdriven systems interrogation of metabolic dysregulation in COVID-19 pathogenesis. Cell Metabol 2020;32:188-202. e5.

65. Xu J, Zhou M, Luo P, Yin Z, Wang S, Liao T, et al. Plasma metabolomic profiling of patients recovered from COVID-19 with pulmonary sequelae 3 months after discharge. Clin Infect Dis 2021:1-12. ciab147. [Online ahead of print].

66. Deguchi H, Banerjee Y, Trauger S, Siuzdak G, Kalisiak E, Fernández JA, et al. Acylcarnitines are anticoagulants that inhibit factor $\mathrm{Xa}$ and are reduced in venous thrombosis, based on metabolomics data. Blood 2015;126:1595-600.

67. Tan CW, Tan JY, Wong WH, Cheong MA, Ng IM, Conceicao EP, et al. Clinical and laboratory features of hypercoagulability in COVID-19 and other respiratory viral infections amongst predominantly younger adults with few comorbidities. Sci Rep 2021;11:1793.

68. Caterino M, Gelzo M, Sol S, Fedele R, Annunziata A, Calabrese C, et al. Dysregulation of lipid metabolism and pathological inflammation in patients with COVID-19. Sci Rep 2021;11:2941.

69. Delafiori J, Navarro LC, Siciliano RF, de Melo GC, Busanello ENB, Nicolau JC, et al. Covid-19 automated diagnosis and risk assessment through metabolomics and machine learning. Anal Chem 2021;93:2471-79.

70. Cartier A, Hla T. Sphingosine 1-phosphate: lipid signaling in pathology and therapy. Science 2019;366:eaar5551.

71. Snider JM, You JK, Wang X, Snider AJ, Hallmark B, Seeds MC, et al. Group IIA secreted phospholipase A 2 plays a central role in the pathobiology of COVID-19. MedRxiv [preprint]. 2021: 2021.02.22.21252237.

72. Sviridov D, Mukhamedova N, Miller YI. Lipid rafts as a therapeutic target. J Lipid Res 2020;61:687-95.

73. Pang Z, Zhou G, Chong J, Xia J. Comprehensive meta-analysis of COVID-19 global metabolomics datasets. Metabolites 2021;11:44.

74. Blasco H, Bessy C, Plantier L, Lefevre A, Piver E, Bernard L, et al. The specific metabolome profiling of patients infected by SARS-COV-2 supports the key role of tryptophan-nicotinamide pathway and cytosine metabolism. Sci Rep 2020;10:16824.

75. Kimhofer T, Lodge S, Whiley L, Gray N, Loo RL, Lawler NG, et al. Integrative modeling of quantitative plasma lipoprotein, metabolic, and amino acid data reveals a multiorgan pathological signature of SARS-CoV-2 infection. J Proteome Res 2020;19:4442-54.

76. Sindelar M, Stancliffe E, Schwaiger-Haber M, Anbukumar DS, Albrecht RA, Liu WC, et al. Longitudinal metabolomics of human plasma reveals robust prognostic markers of COVID-19 disease severity. medRxiv [Preprint] 2021. 02.05.21251173.

77. Cohen EB, Geck RC, Toker A. Metabolic pathway alterations in microvascular endothelial cells in response to hypoxia. PloS One 2020;15: e0232072.

78. Doğan HO, Şenol O, Bolat S, Yıldız ŞN, Büyüktuna SA, Sarıismailoğlu R, et al. Understanding the pathophysiological changes via untargeted metabolomics in COVID-19 patients. J Med Virol 2021;93:2340-49.

79. Bharadwaj S, Singh M, Kirtipal N, Kang SG. SARS-CoV-2 and glutamine: SARS-CoV-2 triggered pathogenesis via metabolic reprograming of glutamine in host cells. Front Mol Biosci 2021;7: 627842.

80. Koziel A, Jarmuszkiewicz W. Hypoxia and aerobic metabolism adaptations of human endothelial cells. Pflügers Archiv 2017; 469:815-27.

81. Hou E, Sun N, Zhang F, Zhao C, Usa K, Liang M, et al. Malate and aspartate increase L-arginine and nitric oxide and attenuate hypertension. Cell Rep 2017;19:1631-39.

82. Sullivan LB, Gui DY, Hosios AM, Bush LN, Freinkman E, Vander Heiden MG. Supporting aspartate biosynthesis is an essential function of respiration in proliferating cells. Cell 2015; 162:552-63.

83. Fraser DD, Slessarev M, Martin CM, Daley M, Patel MA, Miller MR, et al. Metabolomics profiling of critically ill coronavirus disease 2019 patients: identification of diagnostic and prognostic biomarkers. Crit Care Explor 2020;2: e0272.

84. Wu G, Morris SM Jr. Arginine metabolism: nitric oxide and beyond. Biochem J 1998;336:1-17.

85. Laube G, Bernstein HG. Agmatine: multifunctional arginine metabolite and magic bullet in clinical neuroscience? Biochem J 2017;474:2619-40.

86. Bronte V, Zanovello P. Regulation of immune responses by L-arginine metabolism. Nat Rev Immunol 2005;5:641-54.

87. Morris SM, Jr. Arginine: master and commander in innate immune responses. Sci Signal 2010;3:pe27.

88. Geiger R, Rieckmann JC, Wolf T, Basso C, Feng Y, Fuhrer T, et al. $\mathrm{L}$-arginine modulates $\mathrm{T}$ cell metabolism and enhances survival and anti-tumor activity. Cell 2016;167:829-42. e13.

89. Wijnands KA, Castermans TM, Hommen MP, Meesters DM, Poeze $M$. Arginine and citrulline and the immune response in sepsis. Nutrients 2015;7:1426-63.

90. Alexander JW, Supp DM. Role of arginine and omega-3 fatty acids in wound healing and infection. Adv Wound Care 2014;3:682-90.

91. Tan T, Khoo B, Mills EG, Phylactou M, Patel B, Eng PC, et al. Association between high serum total cortisol concentrations and mortality from COVID-19. Lancet Diabetes Endocrinol 2020;8: 659-60.

92. Migaud M, Gandotra S, Chand HS, Gillespie MN, Thannickal VJ, Langley RJ. Metabolomics to predict antiviral drug efficacy in COVID-19. Am J Respir Cell Mol Biol 2020;63:396-98.

93. Lee SM, Park HY, Suh YS, Yoon EH, Kim J, Jang WH, et al. Inhibition of acute lethal pulmonary inflammation by the IDO-AhR pathway. Proc Natl Acad Sci U S A 2017;114:E5881-90.

94. Wannemacher RW, Jr., Klainer AS, Dinterman RE, Beisel WR. The significance and mechanism of an increased serum phenylalanine-tyrosine ratio during infection. Am J Clin Nutr 1976;29:997-1006.

95. Huang SS, Lin JY, Chen WS, Liu MH, Cheng CW, Cheng ML, et al. Phenylalanine- and leucine-defined metabolic types identify high mortality risk in patients with severe infection. Int J Infect Dis 2019;85:143-9.

96. Yeoh YK, Zuo T, Lui GC, Zhang F, Liu Q, Li AY, et al. Gut microbiota composition reflects disease severity and dysfunctional immune responses in patients with COVID-19. Gut 2021;70:698-706. 
97. Dhar D, Mohanty A. Gut microbiota and Covid-19- possible link and implications. Virus Res 2020;285:198018.

98. Angel PM. On the cutting edge of translational research. Clin Chem 2021;67:583-4.

99. Fischer JE, Rosen HM, Ebeid AM, James JH, Keane JM, Soeters PB. The effect of normalization of plasma amino acids on hepatic encephalopathy in man. Surgery 1976;80:77-91.
100. Nardacci R, Colavita F, Castilletti C, Lapa D, Matusali G, Meschi S, et al. Evidences for lipid involvement in SARS-CoV-2 cytopathogenesis. Cell Death Dis 2021;12:263.

101. Mussap M, Noto A, Piras C, Atzori L, Fanos V. Slotting metabolomics into routine precision medicine. Expert Rev Precis Med Drug Dev 2021;6:173-87. 